\title{
Review Article \\ Glucose, Insulin, and Oxygen Interplay in Placental Hypervascularisation in Diabetes Mellitus
}

\author{
Silvija Cvitic, ${ }^{1,2}$ Gernot Desoye, ${ }^{1}$ and Ursula Hiden ${ }^{1}$ \\ ${ }^{1}$ Department of Obstetrics and Gynecology, Medical University of Graz, Auenbruggerplatz 14, 8036 Graz, Austria \\ ${ }^{2}$ Institute of Cell Biology, Histology and Embryology, Medical University of Graz, Harrachgasse 21, 8010 Graz, Austria \\ Correspondence should be addressed to Silvija Cvitic; silvija.cvitic@medunigraz.at
}

Received 19 May 2014; Accepted 6 August 2014; Published 2 September 2014

Academic Editor: Nathalie Bardin

Copyright (c) 2014 Silvija Cvitic et al. This is an open access article distributed under the Creative Commons Attribution License, which permits unrestricted use, distribution, and reproduction in any medium, provided the original work is properly cited.

\begin{abstract}
The placental vasculature rapidly expands during the course of pregnancy in order to sustain the growing needs of the fetus. Angiogenesis and vascular growth are stimulated and regulated by a variety of growth factors expressed in the placenta or present in the fetal circulation. Like in tumors, hypoxia is a major regulator of angiogenesis because of its ability to stimulate expression of various proangiogenic factors. Chronic fetal hypoxia is often found in pregnancies complicated by maternal diabetes as a result of fetal hyperglycaemia and hyperinsulinemia. Both are associated with altered levels of hormones, growth factors, and proinflammatory cytokines, which may act in a proangiogenic manner and, hence, affect placental angiogenesis and vascular development. Indeed, the placenta in diabetes is characterized by hypervascularisation, demonstrating high placental plasticity in response to diabetic metabolic derangements. This review describes the major regulators of placental angiogenesis and how the diabetic environment in utero alters their expression. In the light of hypervascularized diabetic placenta, the focus was placed on proangiogenic factors.
\end{abstract}

\section{Diabetes in Pregnancy}

With the rise of maternal obesity in the Western world, diabetes in pregnancy has become more prevalent and affects a wide range of 3 to $20 \%$ of pregnancies. Diabetes in pregnancy comprises several metabolic diseases including gestational diabetes mellitus (GDM), a maternal glucose intolerance that clinically manifests in the 2 nd gestational trimester, and type 1 and type 2 diabetes mellitus (T1D, T2D). These diseases cause increased short term fetal risks, foremost increased fetal fat accretion, but they also predispose the offspring to develop metabolic disorders or cardiovascular disease in later life $[1,2]$. The placenta as the essential fetal organ nourishing fetal demands is characterized by various changes in morphology and function which may contribute to the fetal complications of diabetes. Particularly the fetoplacental vasculature and endothelium were shown to be susceptible to the diabetic intrauterine environment. Thus, diabetes associated derangements of factors regulating angiogenesis are a major cause of altered placental angiogenesis and hypervascularisation in diabetes [3-9].

\section{Placental Angiogenesis in Normal Pregnancy}

The central role of the placenta in pregnancy is highlighted by the fact that it is the first fetal organ to develop [10]. The placenta is highly vascularized to allow adequate oxygen and nutrient transfer from mother to fetus and back transfer of fetal waste products to the mother. Placental vascular development is tightly regulated by pro- and antiangiogenic factors and is divided into two stages. The first stage of vessel development, vasculogenesis, begins at day 21 after conception when a vascular plexus forms by differentiation of pluripotent mesenchymal progenitor cells into endothelial cells. In the second stage, these first vessels connect and further expand by angiogenesis that continues from day 32 after conception until delivery [11].

\section{Regulation of Placental Angiogenesis}

Various growth factors have been implicated in the regulation and stimulation of angiogenesis in the human placenta with 
TABLE 1: In vitro expression of receptors of proangiogenic factors in the fetoplacental endothelium in normal third trimester human placenta.

\begin{tabular}{lcccc}
\hline \multirow{2}{*}{$\begin{array}{l}\text { Angiogenic factors } \\
\text { Gene symbol }\end{array}$} & Rene symbol & RefSeq ID & $\begin{array}{c}\text { Mean } \\
\text { intensity }\end{array}$ & Sd \\
\hline VEGFA/PlGF & FLT1/VEGFR1 & NM_002019 & 9.5 & 0.59 \\
\hline VEGFB & KDR/VEGFR2 & NM_002253 & 10.5 & 1.43 \\
\hline \multirow{2}{*}{ FGF1/FGF2 } & FGFR1 & NM_023110 & 9.5 & 0.25 \\
& FGFR2 & NM_000141 & 5.3 & 0.11 \\
& FGFR3 & NM_000142 & 6.8 & 0.13 \\
\hline ANGPT1 & FGFR4 & NM_213647 & 6.1 & 0.09 \\
\hline ANGPT2 & TIE1 & NM_005424 & 10.8 & 0.34 \\
\hline EPO & TEK/TIE2 & NM_000459 & 10.1 & 0.61 \\
\hline TNFA & EPOR & NM_000121 & 7.6 & 0.15 \\
\hline IL6 & TNFR1 & NM_001065 & 10.8 & 0.15 \\
\hline INS & IL6R & NM_001066 & 8.6 & 0.57 \\
\hline IGF1 & INSR & NM_00000208 & 6.7 & 0.28 \\
\hline IGF2 & IGF1R & NM_000875 & 7.5 & 0.70 \\
\hline LEP & IGF2R & NM_000876 & 9.3 & 0.48 \\
\hline ADIPOQ & LEPR & NM_002303 & 8.51 & 0.17 \\
\hline & ADIPOR1 & NM_015999 & 11.6 & 0.11 \\
\hline ADIPOR2 & NM_024551 & 9.6 & 0.18 \\
\hline
\end{tabular}

Mean mRNA signal intensities from arterial $(n=9)$ and venous $(n=9)$ endothelial cells measured by Affymetrix GeneChip Human 1.0 ST arrays (Cvitic et al., unpublished data). Signal intensities range from 1 to 13 . Sd: standard deviation.

distinct actions throughout gestation. Among these the most prominent are vascular endothelial growth factor (VEGF) and fibroblast growth factor 2 (FGF2). Furthermore erythropoietin (EPA), leptin (LEP), adiponectin (ADIPOQ), placental growth factor (PlGF), angiopoietins (ANGPT), and the insulin/insulin-like growth factor (INS/IGF) system have also been demonstrated to promote placental angiogenesis. Their effects are mediated by specific cell surface receptors on the endothelium. Using gene expression analysis we compared expression levels of receptors for these hormones, growth factors, and cytokines in isolated human fetoplacental endothelial cells (Table 1). Indeed, receptors for all aforementioned proangiogenic factors were expressed with highest levels detected for VEGF, angiopoietin, and adiponectin receptors.

In the placenta, proangiogenic factors targeting the fetoplacental endothelium are often produced by neighboring cells such as trophoblasts, macrophages (Hofbauer cells), and smooth muscle cells. Moreover, proangiogenic factors of placental and fetal origin are also present in the fetal circulation. A subgroup of these factors is sensitive to reduced oxygen levels, and hypoxia is able to stimulate their expression.

3.1. Hypoxia. Hypoxia is the major regulator of angiogenesis. In general, it arises when vascular oxygen supply fails to meet metabolic demands. In early pregnancy, however, low oxygen is a physiological condition and drives developmental processes of placenta and embryo proper. During the establishment of the uteroplacental blood flow at the end of the first trimester, fetoplacental oxygen levels steeply rise [12]. Hypoxia affects the expression of multiple proangiogenic factors by regulating their transcription, mRNA stability, and translation. Thus, the low oxygen environment of the early placenta is paralleled by high levels of hypoxia sensitive proangiogenic factors. Mechanisms upregulating their expression under hypoxia are well studied. Whereas global protein synthesis is attenuated under low oxygen by masking the translation initiation sites for ribosomes, specific mRNAs contain alternative, internal ribosome binding sites (IRES) and are preferentially translated. Examples for mRNAs containing IRES include proangiogenic molecules, such as VEGF, and hypoxia inducible factors (HIFs), such as HIF1A. HIFs subsequently transactivate proangiogenic genes by binding to hypoxia response elements (HRE) in their promoters, introns, or enhancers [13].

3.2. VEGF System. The VEGF system constitutes a family of growth factors and their receptors, which are important regulators of blood vessel formation. With the founding factor and most important member, VEGFA (also known as VEGF), this family includes placental growth factor (PlGF), VEGFB, VEGFC, and VEGFD. VEGFs mediate their biological function by a family of protein tyrosine kinase receptors, VEGFR1 (Flt1), VEGFR2 (KDR/Flk1), and Flt4 [14].

In early pregnancy, VEGF is a key driver of placental vascular development and is held responsible for differentiation, growth, and aggregation of the endothelial precursors and formation of the haemangiogenic cords [15]. While villous trophoblasts initiate formation of first placental vessels by secretion of VEGF in the first trimester, it seems that placental macrophages and other stromal cells, for example, smooth muscle cells, take over angiogenic control at later stages of pregnancy [16-18]. VEGFR2 is expressed on the fetoplacental endothelium $[19,20]$ and mediates mitogenic cellular responses (reviewed in [21]), whereas VEGFR1 localizes to placental macrophages and trophoblast [19] and is an important regulator of VEGFR2 signalling (reviewed in [21]). As for VEGF, the expression of VEGFR2 is most intense in the early stages of pregnancy and declines steeply as pregnancy advances $[20,22]$.

In contrast to VEGF, the expression of PlGF and the soluble form of VEGFR1 (sFlt1) increase towards term [2325]. sFlt1 captures free VEGF and prevents its binding to cell surface receptors, Flt1 and KDR, which further attenuates proangiogenic VEGF signaling in the third trimester, when VEGF levels are decreasing. PlGF is expressed in the syncytiotrophoblast [18] and in the smooth muscle cells around the fetoplacental vessels [26] and it stimulates the formation of highly branched capillary networks $[27,28]$. In vitro, PlGF stimulates proliferation of microvascular endothelial cells from human term placenta [29].

Oxygen tension is the key physiological regulator of both VEGF expression and PlGF expression. Hypoxia regulates 
VEGF transcription at the transcriptional level through HREs and posttranscriptionally via IRESs [18]. A similar posttranscriptional regulation was also demonstrated for PlGF [30].

3.3. FGF System. The fibroblast growth factor (FGF) system encompasses 22 members of the heparin-binding fibroblast growth factor family (FGF1 to 10 and FGF16 to 23) and four FGF receptors (FGFR1 to 4) (reviewed in [31]). Basic FGF (bFGF or FGF2) exerts proangiogenic functions on endothelial cells by binding to tyrosine kinase receptors FGFR1 and FGFR2. These functions include stimulation of proliferation, ECM degradation, migration, and modulation of cell-cell interactions (reviewed by [32]). In early placenta, FGF2 is thought to be involved in the recruitment of haemangiogenic progenitor cells, as its expression, similar to VEGF, reaches a maximum in this period of gestation. At term of gestation FGF2 is predominantly expressed in the syncytiotrophoblast, villous stroma, and fetal vessels [3335]. FGFR1 parallels FGF2 expression [33], thus making the fetoplacental endothelium a target of FGF2 action. Similar to VEGF, FGF2 promoters harbor also both HREs and IRES, which mediate the regulation by hypoxia at the translational and posttranslational levels. The prevailing mechanism seems to be cell type specific [36].

3.4. Angiopoietin System. Whilst the VEGF system plays a key role in vessel sprouting and new vessel initiation, angiopoietins have a role in remodeling and maturation phases [37]. Establishment and maintenance of the outer layers of the vessel walls are thought to be controlled, at least in part, by the balance of angiopoietin 1 (ANGPT1) and angiopoietin 2 (ANGPT2), interacting with the angiopoietin receptors Tiel and Tie2 [38]. Accordingly, ANGPT1 and ANGPT2 mRNA and protein have been detected in perivascular cells of immature intermediate villi [39], where larger arterioles/arteries and venules/veins develop. Both Tiel and Tie2 mRNA localize to placental trophoblast and vascular endothelium [40, 41]. ANGPT2 belongs to the hypoxia sensitive proangiogenic factors and is regulated by HRE mediated transcriptional induction and by increasing mRNA stability $[42,43]$.

3.5. EG-VEGF/PROKR System. A novel family of angiogenic mitogens with high tissue specificity composed of EGVEGF/PROK1 and PROK2 and the respective receptors, PROKR1 and PROKR2, has been characterized (reviewed in [44]). Whereas PROK2 mainly associates with the nervous system, EG-VEGF is associated with the reproductive tract including the placenta $[45,46]$. EG-VEGF is mainly localized to syncytiotrophoblast with a mild expression in cytotrophoblast [47]. It has a strong vascular bed specificity and promotes proliferation, migration, tube-like formation, and permeability of placental microvascular endothelial cells without affecting angiogenesis in HUVEC [48]. EG-VEGF receptor PROKR1 is abundant in the cytotrophoblast, in the placental microvascular endothelial cells, and in the Hofbauer cells, whereas PROKR2 is expressed in the syncytiotrophoblast, Hofbauer cells, and extravillous trophoblast $[47,49,50]$. The oxygen tension regulates the expression of both EG-VEGF and the receptor PROKR1 at the transcriptional level [47].

3.6. Erythropoietin (EPO). Erythropoietin (EPO) is a hormone that regulates erythropoiesis in an oxygen-dependent manner. Generally, it is produced by perisinusoidal cells in the liver in the fetal and perinatal period and by peritubular interstitial fibroblasts in the kidney in adults [51]. The nonhematopoietic actions of EPO include regulation of angiogenesis during embryonic development [52], mitogenesis, stimulation of circulating endothelial progenitor cells, and cardioprotective effects in the ischemic heart by inhibiting apoptosis of cardiac myocytes [53, 54].

The placenta is also a source of EPO production, because EPO expression has been shown in various trophoblast subpopulations throughout gestation [55]. In addition, the EPO receptor (EPOR) was identified in villous and extravillous cytotrophoblast and syncytiotrophoblast at all gestational stages and also by cells within the villous core including fetoplacental endothelial cells [56].

EPO synthesis is primarily stimulated by hypoxia at the transcriptional level by HIF binding to HRE elements present in the EPO gene (reviewed in [57]). In addition, recent evidence suggests hypoxia regulation of EPO expression also at the translational level that does not involve IRES elements [58].

3.7. IL6 and TNFA. Interleukin 6 (IL6) and tumor necrosis factor alpha (TNFA) are multifunctional cytokines with main functions in the inflammatory response. In general, IL6 is produced by a variety of cell types, that is, macrophages, muscle cells, fibroblasts, and epithelial cells $[59,60]$, while TNFA is mainly produced by activated macrophages [61]. Both cytokines are also expressed by the human placenta.

In the first trimester placenta, IL6 expression is moderate and increases up to 4 -fold in the third trimester placenta. In early pregnancy IL6 expression is observed in trophoblasts and fetal vessels $[62,63]$, with potential implication in angiogenesis and vascular remodeling [64]. IL6 acts by binding to an IL6-specific receptor, IL6R, which is expressed by placental trophoblasts and fetoplacental endothelial cells [65]. Hypoxia is reported to increase transcription, translation, and release of IL6 gene product from endothelial and smooth muscle cells [66].

TNFA mRNA and protein were also identified in first trimester villi, with strong prevalence in the syncytiotrophoblast and low to none in cytotrophoblasts and villous stromal cells. In term placentas, strong TNFA expression was observed in syncytiotrophoblast and villous stromal cells [67]. TNF signalling is mediated through two receptors, TNFR1 and TNFR2, which are expressed also in fetoplacental cells (reviewed in [68]). Regulation of TNFA transcription is complex and cell type specific [69]. Although TNFA mRNA does not contain HRE, chronic hypoxia is able to stimulate TNFA expression [70].

3.8. Insulin and IGFs. The insulin/insulin-like growth factor (INS/IGF) system comprises three ligands, insulin and the 
insulin-like growth factors 1 and 2 (IGF1 and IGF2), three cell-surface receptors that mediate the biological effects of the INS and IGFs, insulin (IR) and the IGF1 and IGF2 receptors (IGF1R and IGF2R), and a family of IGF-binding proteins (IGFBPs) (reviewed in [71]).

Insulin and IGFs are implicated in the regulation of fetal and placental growth and development. IGF1 and IGF2 are synthesized in placental mesenchymal cells, such as macrophages and endothelial cells, with little change throughout gestation. However, while IGF1 is present in the trophoblast compartment at all gestational stages, IGF2 is not found in the syncytiotrophoblast and its expression in villous and extravillous cytotrophoblasts in the first trimester becomes undetectable at term of gestation [72-77].

In early pregnancy, the IGF1R is expressed on the villous cytotrophoblasts, the syncytiotrophoblast, and extravillous cytotrophoblast and additionally on placental macrophages and on fetoplacental endothelium in the third trimester [75]. The IR is localized predominantly at the syncytiotrophoblast with low occurrence in cytotrophoblasts in the first trimester. At term, however, IR is found mainly in the fetoplacental vessels [78]. Absent or low expression of insulin and IGF receptors on fetoplacental endothelium in the first trimester suggests that insulin and IGFs regulate fetoplacental angiogenesis only in later stages of pregnancy but will not contribute to placental vasculogenesis.

3.9. Leptin. The adipokine leptin (LEP) regulates food intake and satiety, but it also exerts growth factor and proangiogenic actions. In the placenta it is expressed in cytotrophoblasts, syncytiotrophoblast, amnion, and the fetoplacental endothelial cells $[79,80]$. Most of the leptin produced by the placenta is secreted into the maternal circulation and may contribute to the increased maternal leptin levels during pregnancy [81]. Only $5 \%$ of leptin is secreted in the fetal circulation [82]. Leptin receptor (LEPR) is markedly expressed during the third trimester of pregnancy and is located primarily on the syncytiotrophoblast [83]. In vitro, its expression was also noted in fetoplacental endothelial cells [84].

Similar to VEGF and FGF2, leptin mRNA expression is also regulated by hypoxia, although solely at the transcriptional level by the hypoxia-inducible transcription factor HIF1A [85].

3.10. Adiponectin. Adiponectin (ADIPOQ) is an adipokine with insulin sensitizing properties and is proposed to exert angiogenic actions. ADIPOQ gene and protein expression were reported in the human term placenta, with expression primarily in the syncytiotrophoblast [86]. However a recent study contradicts this finding and shows absence of adiponectin in the term placenta [87]. The expression of the adiponectin receptor, ADIPOR2, but not of ADIPOR1, was observed in the cytoplasm of placental cytotrophoblasts and syncytiotrophoblast suggesting that adiponectin may have a physiological function in the placenta during pregnancy [88]. Whether adiponectin receptors are present in the fetoplacental endothelium has not been fully clarified, but high expression levels of ADIPOR1 and ADIPOR2 in

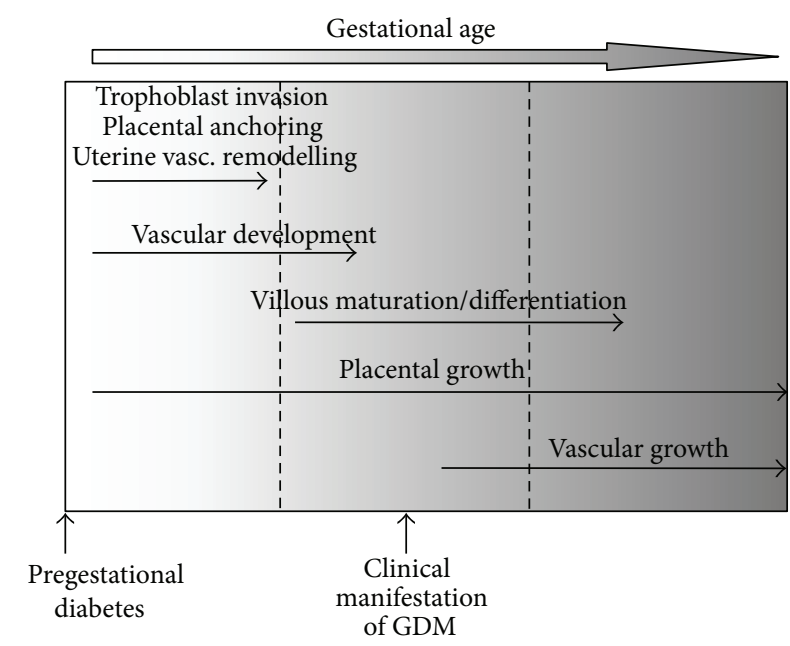

FIGURE 1: Graphical representation of specific windows of placental development susceptible to metabolic insults of pregestational and gestational diabetes, respectively.

isolated fetoplacental cells in vitro (Table 1) may suggest their expression also in vivo.

\section{Placental Angiogenesis in Diabetes Mellitus}

It is well established that maternal diabetes mellitus affects placental vascular development. Depending on the type of diabetes, that is, pregestational (T1D and T2D) or gestational diabetes mellitus (GDM), different windows of placental vascular development are exposed to the diabetic derangements (Figure 1). While pregestational diabetes may affect the entire placental and fetal development, the hyperglycemia of GDM develops during pregnancy and clinically manifests only in the late second trimester. Thus, GDM may have an impact on placental processes occurring in later stages of pregnancy, such as angiogenesis and microvascular remodeling, and will not affect developmental events that occur in early pregnancy, such as vasculogenesis.

This difference in the onset and duration of pregestational diabetes and GDM suggests that the effect of diabetes on placental vascular development and, hence, on the morphology of the placental vascular tree will differ. Indeed, in T1D, three-dimensional power Doppler ultrasound of the fetoplacental vasculature revealed changes in vascular indices already in the first trimester. Thus, T1D affects the placental vasculature already in a period that cannot be affected by GDM. However, the results are conflicting, and both reduced [89] and increased [90] placental vascular indices were reported.

In the third trimester of gestation T1D and GDM lead to similar change of placental vascular structure despite different duration of the diabetic metabolic insult. In T1D the capillary surface area is increased by both longitudinal growth and enhanced branching of villous capillaries [37]. Although less investigated, similar observations were made for the placenta in GDM. There are increased capillary 
branching [8] and capillary surface area [9]. The extent by which capillary branching is increased in T1D and GDM is similar, as reflected by a 2.0 -fold versus a 1.8 -fold increase in the number of redundant connections per villus, respectively $[7,8]$. Further evidence for an impact of maternal diabetes on fetal vascular growth and angiogenesis is provided by findings on longer umbilical cord length in GDM [91] with higher risk for both hyper- and hypocoiled cords [92, 93].

Besides this general finding of placental hypervascularisation, evidence also suggests altered endothelial resistance. Measurements of surface expression of the adherens junctional molecules, vascular-endothelial cadherin (VEcadherin) and beta-catenin ( $\beta$-catenin), revealed a decreased expression in both T1D [94] and GDM placentas [95]. Moreover, in GDM, the tight junctional molecules, occludin and zonula occludens-1 (ZO1), were also reduced [95]. As these molecules play important roles in angiogenesis and barrier function these results implicate a disturbance of these processes in diabetes. Indeed, microscopic observations of cords after GDM pregnancies revealed rupture of the endothelium paralleled by extravasation of blood within Wharton's jelly [96].

These changes in the fetoplacental vasculature in response to maternal diabetes may imply potential differences also in the vasculature of the fetus proper. In fact, fetuses exposed to diabetes have vessel changes in the iris that resolve after birth [97] and an increased risk in developing cardiovascular defects. The prevalence of cardiovascular defects, however, is different between T1D and GDM. Pregestational diabetes associates with $50 \%$ of the investigated cardiac and noncardiac defects in the offspring, while the associations with GDM are weaker and limited to offspring of women with increased prepregnancy BMI [98]. Mechanisms underlying the association of diabetes mellitus with birth defects are not clear. Eriksson and colleagues report a positive correlation between exposure to hyperglycemia during in utero development and the risk of congenital malformations in the infants of diabetic mothers [99], suggesting indeed glucose as the driving force of the detrimental effects that diabetes has on the fetus.

\section{Effect of Maternal Diabetes on Proangiogenic Factors in Placenta and Fetus}

The maternal diabetic environment clearly differs between TID and GDM. However, the emerging metabolic and hormonal changes in the fetus resemble, and it is likely that these changes in the fetus will likewise affect the placental and fetal levels of proangiogenic factors. Some of these changes are summarized in Table 2. The primary origin of fetal derangements in all types of diabetes mellitus is fetal hyperglycaemia resulting from maternal hyperglycaemia. This hyperglycaemia ensues metabolic and hormonal changes in the fetus. Once the fetal pancreas commences to produce and secrete insulin in the late first trimester [100, 101], fetal hyperglycaemia leads to fetal hyperinsulinemia and both stimulate fetal metabolism. Consequently, fetal oxygen demands rise often leading to chronic fetal hypoxia [102-104]. Fetal hypoxia was demonstrated directly by measuring cord
TABLE 2: Expression and levels of proangiogenic factors in placenta and cord blood in pregnancies complicated by different types of diabetes.

\begin{tabular}{|c|c|c|c|}
\hline Factor & $\begin{array}{l}\text { Type of } \\
\text { diabetes }\end{array}$ & Placenta & $\begin{array}{l}\text { Cord } \\
\text { blood }\end{array}$ \\
\hline \multirow{2}{*}{ VEGF } & GDM & $\downarrow$ protein [115] & $\downarrow[108]$ \\
\hline & T1D & $=$ mRNA [35] & $\downarrow[107]$ \\
\hline \multirow{2}{*}{ PlGF } & GDM & $\downarrow$ protein [115] & $\downarrow[108]$ \\
\hline & T1D & $=$ mRNA [35] & $\downarrow[107]$ \\
\hline \multirow{2}{*}{ FGF2 } & GDM & $\begin{array}{c}\uparrow m R N A \text { and protein } \\
{[112,132]}\end{array}$ & $\uparrow[112,142]$ \\
\hline & T1D & $\begin{array}{c}\uparrow m \text { mRNA }[33,111] \\
\uparrow \text { protein }[34] \\
=\text { mRNA }[35]\end{array}$ & $\uparrow[142]$ \\
\hline \multirow{2}{*}{ Angiopoietin } & GDM & $\uparrow \mathrm{mRNA}[113]$ & \\
\hline & $\mathrm{T} 1 \mathrm{D}$ & $=\mathrm{mRNA}[35]$ & \\
\hline \multirow{2}{*}{ Erythropoietin } & GDM & & $\uparrow[103,108]$ \\
\hline & T1D & & $\uparrow[103,126]$ \\
\hline \multirow{2}{*}{ IL6 } & GDM & $\uparrow \mathrm{mRNA}[119]$ & $\downarrow[121]$ \\
\hline & T1D & & \\
\hline \multirow{3}{*}{ TNFA } & & $\uparrow$ protein [120] & $=[122]$ \\
\hline & GDM & $\begin{array}{l}\uparrow \mathrm{mRNA}[113] \\
=\mathrm{mRNA}[119]\end{array}$ & $\downarrow[121]$ \\
\hline & $\mathrm{T} 1 \mathrm{D}$ & & \\
\hline \multirow[t]{2}{*}{ Insulin } & GDM & & $\begin{array}{c}\uparrow[124,125, \\
127,143]\end{array}$ \\
\hline & T1D & & $\begin{array}{c}\uparrow[5,125, \\
126]\end{array}$ \\
\hline \multirow{5}{*}{ IGF1 } & GDM & $\begin{array}{l}=\mathrm{mRNA}[112] \\
\downarrow \mathrm{mRNA}[113]\end{array}$ & $\begin{array}{c}\uparrow[112,144, \\
145]\end{array}$ \\
\hline & T1D & & $=[5]$ \\
\hline & IDDM & & $\uparrow[146]$ \\
\hline & $\mathrm{T} 2 \mathrm{D}$ & & $=[144]$ \\
\hline & $\mathrm{D}$ & $=$ mRNA [147] & $\uparrow[147]$ \\
\hline \multirow{4}{*}{ IGF2 } & GDM & $\uparrow \mathrm{mRNA}[113]$ & $\begin{array}{l}\uparrow[148] \\
=[145]\end{array}$ \\
\hline & T1D & & \\
\hline & IDDM & & $\uparrow[146,148]$ \\
\hline & $\mathrm{D}$ & $\begin{array}{l}=\text { mRNA [147] } \\
\downarrow \text { peptide [147] }\end{array}$ & $\uparrow[147]$ \\
\hline
\end{tabular}

$\uparrow$ indicates elevated levels, $\downarrow$ indicates reduced levels, and $=$ indicates unchanged levels in diabetes.

GDM: gestational diabetes mellitus; T1D: type 1 diabetes; T2D: type 2 diabetes; IDDM: insulin dependent diabetes mellitus without further classification; D: diabetes without further classification.

blood oxygen [102] and indirectly by measuring cord blood EPO levels and by increased erythropoiesis [103-105].

Because of the strong proangiogenic potency of hypoxia [106] through regulating multiple steps of vascular growth, chronic fetal hypoxia as a consequence of maternal diabetes may thus stimulate placental vasculogenesis and angiogenesis by increasing the growth factors expression in the placenta and fetus. As mentioned before, various proangiogenic factors secreted by the placenta or present in the fetal circulation 
harbor hypoxia sensitive regulatory sites, that is, IRES or HREs, and may thus be elevated as a result of maternal diabetes. Potential factors regulated by fetal chronic hypoxia in maternal diabetes include VEGF, PlGF, FGF2, EPO, ANG2, and leptin. However, factors of the diabetic environment other than hypoxia may also contribute and modify its effect.

Parallel to its regulation by oxygen, placental VEGF levels are high in the first trimester when oxygen levels are low and decline thereafter towards term of gestation [16-18]. However, in the third trimester, fetal hypoxia as a result of maternal diabetes does not stimulate VEGF expression. In fact, placental expression and fetal cord levels in maternal T1D and GDM are unchanged or even lower than normal $[107,108]$. Also PlGF levels are not altered in maternal diabetes [109]. Nevertheless, whole placental tissue from GDM pregnancies contains more VEGFR1 (Flt1) and VEGFR2 (Kdr) [110], which may compensate for the reduced VEGF levels and thus maintain VEGF activity.

Similar to VEGF, also FGF2 levels are higher in the low oxygen environment of the first trimester placenta than in the term placenta [111]. However, in contrast to VEGF, FGF2 is increased in placenta and fetal cord blood in diabetic pregnancies $[33,112]$. The presence of an IRES and HRE sequence within its promoter represents a mechanism by which hypoxia increases FGF2 expression and translation [36].

Hypoxia is also known to induce the expression of EGVEGF and PROKR1, but their levels were never investigated in diabetes. Nevertheless, since the EG-VEGF and the receptors, PROKR1 and PROKR2, are predominantly expressed during the first trimester of pregnancy the derangement in the level of these factors would affect placental vasculogenesis [47].

Different from the VEGF and FGF2 system, both of which promote sprouting angiogenesis, the angiopoietin system is a major regulator of vessel maintenance and maturation [37]. ANG2 is transcriptionally regulated by hypoxia. This may explain why ANG2 mRNA expression is increased in the placenta in maternal diabetes [113].

The hormone EPO is also induced by hypoxia and increased in the fetal circulation of diabetic pregnancies at the end of gestation [103]. The EPOR is expressed in fetoplacental vessels [56], making placental endothelial cells a target for EPO action. Experiments in mice revealed that proangiogenic effects of the EPOR are mediated by upregulation of the VEGF/VEGF receptor system [114]. While fetal VEGF levels are unchanged or even lower in maternal diabetes, the VEGFR is increased in the placenta [115]. This would suggest that in a situation of increased fetal oxygen demand fetal and perhaps also placental EPO can promote placental angiogenesis through the VEGF/VEGF receptor system. Although an attractive hypothesis, this awaits demonstration in human.

Collectively, the contribution of hypoxia in altering placental and fetal levels of proangiogenic factors is diverse. While FGF2 and EPO are upregulated in maternal diabetes, the classical hypoxia regulated proangiogenic genes VEGF, PlGF,and ANG2 remain unchanged. This suggests that additional mediators present in the diabetic milieu may also contribute to the diabetes associated hypervascularization.
Hyperglycaemia and hyperinsulinemia are such candidates. They may further modify the effect of hypoxia. The contribution of mediators in diabetes in addition to hypoxia is highlighted by differences in placental vascularization between diabetes and other conditions associated with fetal hypoxia, such as high altitude, anemia, or smoking [116]. While increased branching angiogenesis is a common observation, other vascular features, such as total vascular volume, surface area, and capillary length, are increased in maternal diabetes but remain unchanged in the other hypoxic conditions [116].

In addition to hypoxia, hyperglycaemia is one factor that may further impact placental vascular changes, since it is the main reason causing proinflammatory environment and cytokine derangements that will further act on the endothelium. Hyperglycaemia contributes to the generation of reactive oxygen species (ROS) and, thus, to oxidative stress. ROS are generated on one hand by stimulation of the glucose metabolism and the respiratory chain in the mitochondria and on the other hand by the production of advanced glycation end products (AGE). When binding to their receptor (RAGE), AGE induce the formation of ROS as second messengers, a process also termed ROS signaling (reviewed by [117]). As a speculation, this oxidative stress may then contribute to the proinflammatory environment of diabetes and may affect angiogenesis.

Expression of both IL6 and TNFA is sensitive to oxidative stress. Indeed, hyperglycemia stimulates expression of IL6 in trophoblasts [118] and placental expression of IL6 and TNFA is increased [113, 119, 120], but their levels in the fetal circulation are unchanged or even reduced [121, 122]. Thus, TNFA and IL6 may affect placental angiogenesis locally, that is, in a paracrine manner. TNFA and IL6 are not only regulated by the diabetic environment and they are regulators and initiators of the proinflammatory environment of diabetes. Both modulate the expression of adiponectin and leptin. Moreover, TNFA stimulates DNA binding of HIF1 [123] and thus may augment hypoxia induced transcription.

Besides hypoxia and hyperglycaemia, hyperinsulinemia is another hallmark of changes in the fetal circulation associated with maternal diabetes mellitus [5, 124-127]. The potent role of insulin in angiogenesis of fetoplacental endothelial cells has been shown by in vivo observations and in vitro studies. Fetal cord insulin is positively associated with capillary surface area of the placenta at the end of gestation $[5,128]$. In isolated fetoplacental endothelial cells insulin binding to its receptors stimulates several pathways that promote angiogenesis, including the activation of the small GTPase Racl, eNOS, and expression of the matrix metalloproteinase MT1-MMP [129, 130].

Leptin is regulated by multiple aspects of the fetal diabetic environment. In pregnancies complicated by maternal diabetes mellitus, placental leptin production and fetal plasma leptin is increased $[5,79,113,124,125,127,131,132]$. Correlation of fetal insulin with fetal leptin levels suggests that fetal hyperinsulinemia, by stimulating white adipose tissue growth, the main leptin source, leads to higher leptin production in fetal adipose tissue [133]. Additionally, insulin was recently shown to stimulate leptin expression in human placental explants [134]. However, it is unclear whether this 

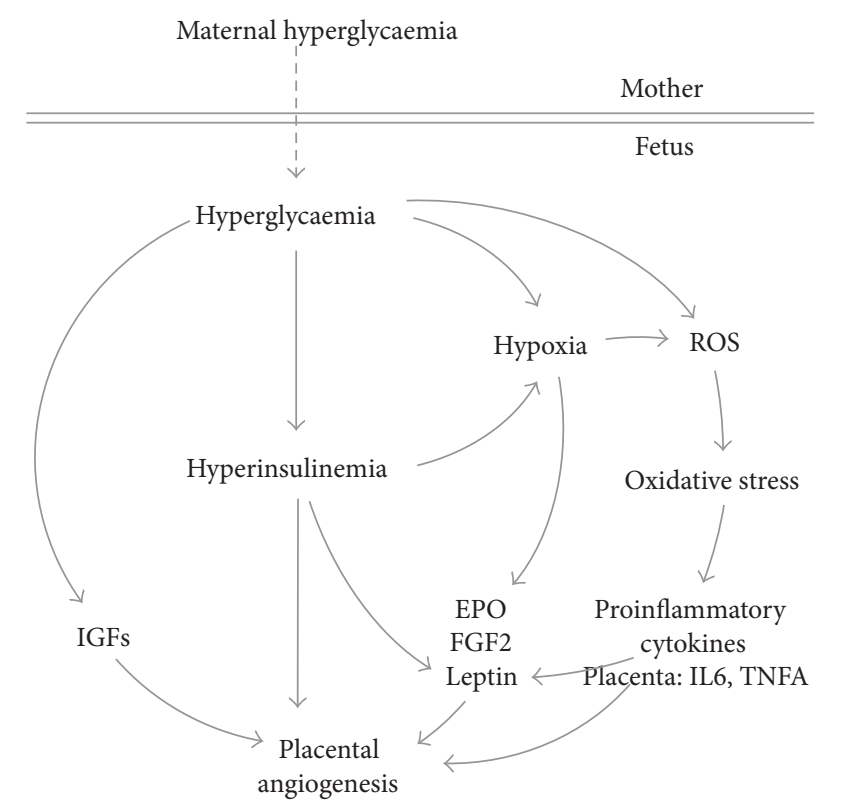

FIGURE 2: Hypothetic scheme indicating how fetal hyperglycaemia, hyperinsulinemia, and hypoxia may induce metabolic, hormonal, and inflammatory changes that may lead to placental hypervascularisation.

leptin will act in a paracrine manner or what proportion is secreted into the fetal circulation. A proinflammatory environment also stimulates leptin secretion. TNFA and IL6 upregulate leptin expression in trophoblasts in vitro $[135,136]$. Furthermore, correlation of fetal leptin levels with fetal EPO levels in T1D [104] parallels the finding that leptin is regulated by hypoxia through transcriptional induction by HIF1 [85] and can thus represent another manifestation of fetal hypoxia in diabetes mellitus.

Similar to leptin, adiponectin is multifactorially regulated. Both, hyperinsulinemia and hypoxia suppress adiponectin concentrations in adipocytes $[137,138]$. Thus, lower levels of adiponectin in the fetal circulation and in the placenta associated with maternal diabetes [85, 86, 139-141] may result from various alterations of the intrauterine environment of diabetes, but reduced levels of the proangiogenic adiponectin suggest that it will not contribute to placental hypervascularisation.

\section{Conclusion}

Diabetes mellitus in human pregnancy strongly affects fetoplacental vascular morphology. The fetal diabetic environment resulting from maternal and, hence, fetal hyperglycemia causes fetal hyperinsulinemia and hypoxia. Hypoxia is a key modulator of angiogenesis and works in concert with the diabetic environment to induce placental hypervascularization (Figure 2).

Whether vascular changes occur also in the fetus proper is still unknown. Altered cord blood levels of the majority of proangiogenic factors, as summarized above, however, may suggest potential consequences in the fetus. This speculation is supported by an increased risk for cardiovascular defects [98] and vessel changes in the iris [97] in offspring born to diabetic mothers.

\section{Conflict of Interests}

The authors declare that there is no conflict of interests regarding the publication of this paper.

\section{References}

[1] A. L. Deierlein, A. M. Siega-Riz, K. Chantala, and A. H. Herring, "The association between maternal glucose concentration and child BMI at age 3 years," Diabetes Care, vol. 34, no. 2, pp. 480$484,2011$.

[2] N. A. West, T. L. Crume, M. A. Maligie, and D. Dabelea, "Cardiovascular risk factors in children exposed to maternal diabetes in utero," Diabetologia, vol. 54, no. 3, pp. 504-507, 2011.

[3] E. Jauniaux and G. J. Burton, "Villous histomorphometry and placental bed biopsy investigation in type I diabetic pregnancies," Placenta, vol. 27, no. 4-5, pp. 468-474, 2006.

[4] T. M. Mayhew, "Enhanced fetoplacental angiogenesis in pregestational diabetes mellitus: the extra growth is exclusively longitudinal and not accompanied by microvascular remodelling," Diabetologia, vol. 45, no. 10, pp. 1434-1439, 2002.

[5] S. M. Nelson, P. M. Coan, G. J. Burton, and R. S. Lindsay, "Placental structure in type 1 diabetes: relation to fetal insulin, leptin, and IGF-I," Diabetes, vol. 58, no. 11, pp. 2634-2641, 2009.

[6] T. M. Mayhew, F. B. Sorensen, J. G. Klebe, and M. R. Jackson, "Growth and maturation of villi in placentae from wellcontrolled diabetic women," Placenta, vol. 15, no. 1, pp. 57-65, 1994.

[7] M. Jirkovská, T. Kučera, J. Kaláb et al., “The branching pattern of villous capillaries and structural changes of placental terminal villi in type 1 diabetes mellitus," Placenta, vol. 33, no. 5, pp. 343351,2012

[8] M. Jirkovská, L. Kubínová, J. Janáček, M. Moravcová, V. Krejčí, and P. Karen, "Topological properties and spatial organization of villous capillaries in normal and diabetic placentas," Journal of Vascular Research, vol. 39, no. 3, pp. 268-278, 2002.

[9] F. Teasdale, "Histomorphometry of the placenta of the diabetic woman: class A diabetes mellitus," Placenta, vol. 2, no. 3, pp. 241$251,1981$.

[10] K. L. Moore and T. V. N. Persaud, Embryologie, Urban \& Fischer, 5th edition, 2007.

[11] D. S. Charnock-Jones, P. Kaufmann, and T. M. Mayhew, "Aspects of human fetoplacental vasculogenesis and angiogenesis. I. Molecular regulation," Placenta, vol. 25, no. 2-3, pp. $103-$ $113,2004$.

[12] E. Jauniaux, A. L. Watson, J. Hempstock, Y.-P. Bao, J. N. Skepper, and G. J. Burton, "Onset of maternal arterial blood flow and placental oxidative stress: a possible factor in human early pregnancy failure," The American Journal of Pathology, vol. 157, no. 6, pp. 2111-2122, 2000.

[13] R. M. Young, S.-J. Wang, J. D. Gordan, X. Ji, S. A. Liebhaber, and M. C. Simon, "Hypoxia-mediated selective mRNA translation by an internal ribosome entry site-independent mechanism," The Journal of Biological Chemistry, vol. 283, no. 24, pp. 1630916319, 2008. 
[14] D. I. R. Holmes and I. Zachary, "The vascular endothelial growth factor (VEGF) family: angiogenic factors in health and disease," Genome Biology, vol. 6, article 209, no. 2, 2005.

[15] F. Shalaby, J. Rossant, T. P. Yamaguchi et al., "Failure of bloodisland formation and vasculogenesis in Flk-1 deficient mice," Nature, vol. 376, no. 6535, pp. 62-66, 1995.

[16] A. Ahmed, X. F. Li, C. Dunk, M. J. Whittle, D. I. Rushton, and T. Rollason, "Colocalisation of vascular endothelial growth factor and its flt-1 receptor in human placenta," Growth Factors, vol. 12, no. 3, pp. 235-243, 1995.

[17] A. M. Sharkey, D. S. Charnock-Jones, C. A. Boocock, K. D. Brown, and S. K. Smith, "Expression of mRNA for vascular endothelial growth factor in human placenta," Journal of Reproduction and Fertility, vol. 99, no. 2, pp. 609-615, 1993.

[18] P. Vuorela, E. Hatva, A. Lymboussaki et al., "Expression of vascular endothelial growth factor and placenta growth factor in human placenta," Biology of Reproduction, vol. 56, no. 2, pp. 489-494, 1997.

[19] D. E. Clark, S. K. Smith, A. M. Sharkey, and D. S. CharnockJones, "Localization of VEGF and expression of its receptors flt and KDR in human placenta throughout pregnancy," Human Reproduction, vol. 11, no. 5, pp. 1090-1098, 1996.

[20] M. Vuckovic, J. Ponting, B. I. Terman, V. Niketic, M. W. Seif, and S. Kumar, "Expression of the vascular endothelial growth factor receptor, KDR, in human placenta," Journal of Anatomy, vol. 188, part 2, pp. 361-366, 1996.

[21] A.-K. Olsson, A. Dimberg, J. Kreuger, and L. Claesson-Welsh, "VEGF receptor signalling-in control of vascular function," Nature Reviews Molecular Cell Biology, vol. 7, no. 5, pp. 359-371, 2006.

[22] K. Kumazaki, M. Nakayama, N. Suehara, and Y. Wada, "Expression of vascular endothelial growth factor, placental growth factor, and their receptors Flt-1 and KDR in human placenta under pathologic conditions," Human Pathology, vol. 33, no. 11, pp. 1069-1077, 2002.

[23] C. Crescimanno, D. Marzioni, M. G. Persico et al., "Expression of bFGF, PlGF and their receptors in the human placenta," Placenta, vol. 16, article A13, 1995.

[24] Y. He, S. K. Smith, K. A. Day, D. E. Clark, D. R. Licence, and D. S. Charnock-Jones, "Alternative splicing of vascular endothelial growth factor (VEGF)-R1 (FLT-1) pre-mRNA is important for the regulation of VEGF activity," Molecular Endocrinology, vol. 13, no. 4, pp. 537-545, 1999.

[25] K. Benirschke, P. Kaufmann, and R. Baergen, Pathology of the Human Placenta, Springer, New York, NY, USA, 5th edition, 2006.

[26] A. Khaliq, X. F. Li, M. Shams et al., "Localisation of placenta growth factor (PIGF) in human term placenta," Growth Factors, vol. 13, no. 3-4, pp. 243-250, 1996.

[27] T. Odorisio, C. Schietroma, M. L. Zaccaria et al., "Mice overexpressing placenta growth factor exhibit increased vascularization and vessel permeability," Journal of Cell Science, vol. 115, no. 12, pp. 2559-2567, 2002.

[28] M. Autiero, J. Waltenberger, D. Communi et al., "Role of PlGF in the intra- and intermolecular cross talk between the VEGF receptors Flt1 and Flk1," Nature Medicine, vol. 9, no. 7, pp. 936943, 2003.

[29] I. Lang, M. A. Pabst, U. Hiden et al., "Heterogeneity of microvascular endothelial cells isolated from human term placenta and macrovascular umbilical vein endothelial cells," European Journal of Cell Biology, vol. 82, no. 4, pp. 163-173, 2003.
[30] L. Xiang, R. Varshney, N. A. Rashdan, J. H. Shaw, and P. G. Lloyd, "Placenta growth factor and vascular endothelial growth factor a have differential, cell-type specific patterns of expression in vascular cells," Microcirculation, vol. 21, no. 5, pp. 368-379, 2014.

[31] A. Beenken and M. Mohammadi, "The FGF family: biology, pathophysiology and therapy," Nature Reviews Drug Discovery, vol. 8, no. 3, pp. 235-253, 2009.

[32] M. Presta, P. Dell'Era, S. Mitola, E. Moroni, R. Ronca, and M. Rusnati, "Fibroblast growth factor/fibroblast growth factor receptor system in angiogenesis," Cytokine and Growth Factor Reviews, vol. 16, no. 2, pp. 159-178, 2005.

[33] E. Arany and D. J. Hill, "Fibroblast growth factor-2 and fibroblast growth factor receptor-1 mRNA expression and peptide localization in placentae from normal and diabetic pregnancies," Placenta, vol. 19, no. 2-3, pp. 133-142, 1998.

[34] D. W. Burleigh, K. Stewart, K. M. Grindle, H. H. Kay, and T. G. Golos, "Influence of maternal diabetes on placental fibroblast growth factor-2 expression, proliferation, and apoptosis," Journal of the Society for Gynecologic Investigation, vol. 11, no. 1, pp. 36-41, 2004.

[35] J. Janota, J. Pomyje, D. Toth et al., “ Expression of angiopoietic factors in normal and type-I diabetes human placenta: a pilot study," The European Journal of Obstetrics \& Gynecology and Reproductive Biology, vol. 111, no. 2, pp. 153-156, 2003.

[36] S. M. Black, J. M. DeVol, and S. Wedgwood, "Regulation of fibroblast growth factor-2 expression in pulmonary arterial smooth muscle cells involves increased reactive oxygen species generation," The American Journal of Physiology-Cell Physiology, vol. 294, no. 1, pp. C345-C354, 2008.

[37] G. Thurston, "Role of Angiopoietins and Tie receptor tyrosine kinases in angiogenesis and lymphangiogenesis," Cell and Tissue Research, vol. 314, no. 1, pp. 61-68, 2003.

[38] D. Hanahan, "Signaling vascular morphogenesis and maintenance," Science, vol. 277, no. 5322, pp. 48-50, 1997.

[39] E. Geva, D. G. Ginzinger, C. J. Zaloudek, D. H. Moore, A. Byrne, and R. B. Jaffe, "Human placental vascular development: vasculogenic and angiogenic (branching and nonbranching) transformation is regulated by vascular endothelial growth factor-A, angiopoietin-1, and angiopoietin-2," Journal of Clinical Endocrinology and Metabolism, vol. 87, no. 9, pp. 4213-4224, 2002.

[40] Y. Seval, L. Sati, C. Celik-Ozenci, O. Taskin, and R. Demir, "The distribution of angiopoietin-1, angiopoietin-2 and their receptors tie-1 and tie-2 in the very early human placenta," Placenta, vol. 29, no. 9, pp. 809-815, 2008.

[41] E. G. Zhang, S. K. Smith, P. N. Baker, and D. S. Charnock-Jones, "The regulation and localization of angiopoietin-1, -2, and their receptor Tie2 in normal and pathologic human placentae," Molecular Medicine, vol. 7, no. 9, pp. 624-635, 2001.

[42] B. D. Kelly, S. F. Hackett, K. Hirota et al., "Cell type-specific regulation of angiogenic growth factor gene expression and induction of angiogenesis in nonischemic tissue by a constitutively active form of hypoxia-inducible factor 1,' Circulation Research, vol. 93, no. 11, pp. 1074-1081, 2003.

[43] P. Pichiule, J. C. Chavez, and J. C. LaManna, "Hypoxic regulation of angiopoietin-2 expression in endothelial cells," The Journal of Biological Chemistry, vol. 279, no. 13, pp. 12171-12180, 2004.

[44] N. Alfaidy, P. Hoffmann, H. Boufettal et al., "The multiple roles of EG-VEGF/PROK1 in normal and pathological placental 
angiogenesis," BioMed Research International, vol. 2014, Article ID 451906, 10 pages, 2014.

[45] J. Lecouter, J. Kowalski, J. Foster et al., "Identification of an angiogenic mitogen selective for endocrine gland endothelium," Nature, vol. 412, no. 6850, pp. 877-884, 2001.

[46] R. Lin, J. LeCouter, J. Kowalski, and N. Ferrara, "Characterization of endocrine gland-derived vascular endothelial growth factor signaling in adrenal cortex capillary endothelial cells," The Journal of Biological Chemistry, vol. 277, no. 10, pp. 87248729, 2002.

[47] P. Hoffmann, J.-J. Feige, and N. Alfaidy, "Expression and oxygen regulation of endocrine gland-derived vascular endothelial growth factor/prokineticin-1 and its receptors in human placenta during early pregnancy," Endocrinology, vol. 147, no. 4, pp. 1675-1684, 2006

[48] S. Brouillet, P. Hoffmann, M. Benharouga et al., "Molecular characterization of EG-VEGF-mediated angiogenesis: differential effects on microvascular and macrovascular endothelial cells," Molecular Biology of the Cell, vol. 21, no. 16, pp. 2832-2843, 2010.

[49] F. C. Denison, S. Battersby, A. E. King, M. Szuber, and H. N. Jabbour, "Prokineticin-1: a novel mediator of the inflammatory response in third-trimester human placenta," Endocrinology, vol. 149, no. 7, pp. 3470-3477, 2008.

[50] M. Matjila, R. Millar, Z. van der Spuy, and A. Katz, "The differential expression of Kiss1, MMP9 and angiogenic regulators across the feto-maternal interface of healthy human pregnancies: implications for trophoblast invasion and vessel development," PLoS ONE, vol. 8, no. 5, Article ID e63574, 2013.

[51] Z. A. Haroon, K. Amin, X. Jiang, and M. O. Arcasoy, "A novel role for erythropoietin during fibrin-induced wound-healing response," The American Journal of Pathology, vol. 163, no. 3, pp. 993-1000, 2003.

[52] N. Kertesz, J. Wu, T. H.-P. Chen, H. M. Sucov, and H. Wu, “The role of erythropoietin in regulating angiogenesis," Developmental Biology, vol. 276, no. 1, pp. 101-110, 2004.

[53] A. F. Tramontano, R. Muniyappa, A. D. Black et al., "Erythropoietin protects cardiac myocytes from hypoxia-induced apoptosis through an Akt-dependent pathway," Biochemical and Biophysical Research Communications, vol. 308, no. 4, pp. 990994, 2003.

[54] F. H. Bahlmann, K. de Groot, J.-M. Spandau et al., "Erythropoietin regulates endothelial progenitor cells," Blood, vol. 103, no. 3, pp. 921-926, 2004.

[55] K. P. Conrad, D. F. Benyo, A. Westerhausen-Larsen, and T. M. Miles, "Expression of erythropoietin by the human placenta," The FASEB Journal, vol. 10, no. 7, pp. 760-768, 1996.

[56] D. F. Benyo and K. P. Conrad, "Expression of the erythropoietin receptor by trophoblast cells in the human placenta," Biology of Reproduction, vol. 60, no. 4, pp. 861-870, 1999.

[57] W. Jelkmann, "Erythropoietin after a century of research: younger than ever," European Journal of Haematology, vol. 78, no. 3, pp. 183-205, 2007.

[58] C. Barbosa and L. Romao, "Translation of the human erythropoietin transcript is regulated by an upstream open reading frame in response to hypoxia," RNA, vol. 20, no. 5, pp. 594-608, 2014.

[59] T. Hirano, S. Akira, T. Taga, and T. Kishimoto, "Biological and clinical aspects of interleukin 6," Immunology Today, vol. 11, no. 12, pp. 443-449, 1990.
[60] T. Kameda, N. Matsuzaki, K. Sawai et al., "Production of interleukin- 6 by normal human trophoblast," Placenta, vol. 11, no. 3, pp. 205-213, 1990.

[61] M. Bette, M. K.-H. Schafer, N. van Rooijen, E. Weihe, and B. Fleischer, "Distribution and kinetics of superantigen-induced cytokine gene expression in mouse spleen," Journal of Experimental Medicine, vol. 178, no. 5, pp. 1531-1539, 1993.

[62] W. A. Bennett, S. Lagoo-Deenadayalan, J. A. Stopple et al., "Cytokine expression by first-trimester human chorionic villi," The American Journal of Reproductive Immunology, vol. 40, no. 5, pp. 309-318, 1998.

[63] W. A. Bennett, S. Lagoo-Deenadayalan, N. S. Whitworth et al., "First-trimester human chorionic villi express both immunoregulatory and inflammatory cytokines: a role for interleukin-10 in regulating the cytokine network of pregnancy," The American Journal of Reproductive Immunology, vol. 41, no. 1, pp. 70-78, 1999.

[64] B. Motro, A. Itin, L. Sachs, and E. Keshet, "Pattern of interleukin 6 gene expression in vivo suggests a role for this cytokine in angiogenesis," Proceedings of the National Academy of Sciences of the United States of America, vol. 87, no. 8, pp. 3092-3096, 1990.

[65] A. Steinborn, M. Geisse, and M. Kaufmann, "Expression of cytokine receptors in the placenta in term and preterm labour," Placenta, vol. 19, no. 2-3, pp. 165-170, 1998.

[66] S. F. Yan, I. Tritto, D. Pinsky et al., "Induction of interleukin 6 (IL-6) by hypoxia in vascular cells: central role of the binding site for nuclear factor-IL-6," The Journal of Biological Chemistry, vol. 270, no. 19, pp. 11463-11471, 1995.

[67] H.-L. Chen, Y. Yang, X.-L. Hu, K. K. Yelavarthi, J. L. Fishback, and J. S. Hunt, "Tumor necrosis factor alpha mRNA and protein are present in human placental and uterine cells at early and late stages of gestation," The American Journal of Pathology, vol. 139, no. 2, pp. 327-335, 1991.

[68] S. Haider and M. Knöfler, "Human tumour necrosis factor: physiological and pathological roles in placenta and endometrium," Placenta, vol. 30, no. 2, pp. 111-123, 2009.

[69] E. Y. Tsai, J. Yie, D. Thanos, and A. E. Goldfeld, "Cell-typespecific regulation of the human tumor necrosis factor alpha gene in B cells and T cells by NFATp and ATF-2/JUN," Molecular and Cellular Biology, vol. 16, no. 10, pp. 5232-5244, 1996.

[70] S. K. Leeper-Woodford and K. Detmer, "Acute hypoxia increases alveolar macrophage tumor necrosis factor activity and alters NF- $\kappa \mathrm{B}$ expression," The American Journal of Physiology-Lung Cellular and Molecular Physiology, vol. 276, no. 6, pp. L909L916, 1999.

[71] D. Le Roith, "Seminars in medicine of the Beth Israel Deaconess Medical Center. Insulin-like growth factors," The New England Journal of Medicine, vol. 336, no. 9, pp. 633-640, 1997.

[72] R. Birnbacher, G. Amann, H. Breitschopf, H. Lassmann, G. Suchanek, and P. Heinz-Erian, "Cellular localization of insulinlike growth factor II mRNA in the human fetus and the placenta: Detection with a digoxigenin-labeled cRNA probe and immunocytochemistry," Pediatric Research, vol. 43, no. 5, pp. 614-620, 1998.

[73] H. Dalçik, M. Yardimoğlu, B. Vural et al., "Expression of insulinlike growth factor in the placenta of intrauterine growthretarded human fetuses," Acta Histochemica, vol. 103, no. 2, pp. 195-207, 2001.

[74] V. K. M. Han and A. M. Carter, "Spatial and temporal patterns of expression of messenger RNA for insulin-like growth factors 
and their binding proteins in the placenta of man and laboratory animals," Placenta, vol. 21, no. 4, pp. 289-305, 2000.

[75] U. Hiden, E. Glitzner, M. Hartmann, and G. Desoye, "Insulin and the IGF system in the human placenta of normal and diabetic pregnancies," Journal of Anatomy, vol. 215, no. 1, pp. 6068, 2009.

[76] D. J. Hill, D. R. Clemmons, S. C. Riley, N. Bassett, and J. R. G. Challis, "Immunohistochemical localization of insulin-like growth factors (IGFs) and IGF binding proteins -1, - 2 and -3 in human placenta and fetal membranes," Placenta, vol. 14, no. 1, pp. 1-12, 1993.

[77] B. M. Thomsen, H. V. Clausen, L. G. Larsen, L. Nürnberg, B. Ottesen, and H. K. Thomsen, "Patterns in expression of insulinlike growth factor-II and of proliferative activity in the normal human first and third trimester placenta demonstrated by non-isotopic in situ hybridization and immunohistochemical staining for MIB-1," Placenta, vol. 18, no. 2-3, pp. 145-154, 1997.

[78] G. Desoye, M. Hartmann, and C. J. Jones, "Location of insulin receptors in the placenta and its progenitor tissues," Microscopy Research and Technique, vol. 38, no. 1-2, pp. 63-75, 1997.

[79] R. G. Lea, D. Howe, L. T. Hannah, O. Bonneau, L. Hunter, and N. Hoggard, "Placental leptin in normal, diabetic and fetal growthretarded pregnancies," Molecular Human Reproduction, vol. 6, no. 8, pp. 763-769, 2000.

[80] M. C. Henson, K. F. Swan, and J. S. O’Neil, “Expression of placental leptin and leptin receptor transcripts in early pregnancy and at term," Obstetrics and Gynecology, vol. 92, no. 6, pp. 1020-1028, 1998.

[81] S. Hauguel-de Mouzon, J. Lepercq, and P. Catalano, "The known and unknown of leptin in pregnancy," American Journal of Obstetrics \& Gynecology, vol. 194, no. 6, pp. 1537-1545, 2006.

[82] N. Hoggard, J. Crabtree, S. Allstaff, D. R. Abramovich, and P. Haggarty, "Leptin secretion to both the maternal and fetal circulation in the ex vivo perfused human term placenta," Placenta, vol. 22, no. 4, pp. 347-352, 2001.

[83] M. C. Henson and V. D. Castracane, "Leptin in pregnancy: an update," Biology of Reproduction, vol. 74, no. 2, pp. 218-229, 2006.

[84] M. Gauster, U. Hiden, M. van Poppel et al., "Dysregulation of placental endothelial lipase in obese women with gestational diabetes mellitus," Diabetes, vol. 60, no. 10, pp. 2457-2464, 2011.

[85] A. Grosfeld, J. André, S. H.-D. Mouzon, E. Berra, J. Pouysségur, and M. Guerre-Millo, "Hypoxia-inducible factor 1 transactivates the human leptin gene promoter," The Journal of Biological Chemistry, vol. 277, no. 45, pp. 42953-42957, 2002.

[86] J. Chen, B. Tan, E. Karteris et al., "Secretion of adiponectin by human placenta: Differential modulation of adiponectin and its receptors by cytokines," Diabetologia, vol. 49, no. 6, pp. 12921302, 2006.

[87] M. Haghiac, S. Basu, L. Presley et al., "Patterns of Adiponectin expression in term pregnancy; impact of obesity," The Journal of Clinical Endocrinology and Metabolism. In press.

[88] J. E. Caminos, R. Nogueiras, R. Gallego et al., "Expression and regulation of adiponectin and receptor in human and rat placenta," The Journal of Clinical Endocrinology \& Metabolism, vol. 90, no. 7, pp. 4276-4286, 2005.

[89] G. Rizzo, A. Capponi, M. E. Pietrolucci, E. Aiello, and D. Arduini, "First trimester placental volume and three dimensional power doppler ultrasonography in type I diabetic pregnancies," Prenatal Diagnosis, vol. 32, no. 5, pp. 480-484, 2012.
[90] N. L. Gonzalez Gonzalez, E. Gonzalez Davila, A. Castro, E. Padron, and W. Plasencia, "Effect of pregestational diabetes mellitus on first trimester placental characteristics: threedimensional placental volume and power Doppler indices," Placenta, vol. 35, no. 3, pp. 147-151, 2014.

[91] L. Georgiadis, L. Keski-Nisula, and M. Harju, "Umbilical cord length in singleton gestations: a finnish population-based retrospective register study," Placenta, vol. 35, no. 4, pp. 275280, 2014.

[92] M. Ezimokhai, D. E. E. Rizk, and L. Thomas, "Maternal risk factors for abnormal vascular coiling of the umbilical cord," American Journal of Perinatology, vol. 17, no. 8, pp. 441-445, 2000.

[93] T. Chitra, Y. S. Sushanth, and S. Raghavan, "Umbilical coiling index as a marker of perinatal outcome: an analytical study," Obstetrics and Gynecology International, vol. 2012, Article ID 213689, 6 pages, 2012.

[94] L. Leach, C. Gray, S. Staton et al., "Vascular endothelial cadherin and $\beta$-catenin in human fetoplacental vessels of pregnancies complicated by Type 1 diabetes: Associations with angiogenesis and perturbed barrier function," Diabetologia, vol. 47, no. 4, pp. 695-709, 2004.

[95] M. O. Babawale, S. Lovat, T. M. Mayhew, M. J. Lammiman, D. K. James, and L. Leach, "Effects of gestational diabetes on junctional adhesion molecules in human term placental vasculature," Diabetologia, vol. 43, no. 9, pp. 1185-1196, 2000.

[96] S. K. Chakraborty and L. A. Banu, "Microscopic impacts of gestational diabetes mellitus on the umbilical cord," Mymensingh Medical Journal, vol. 22, no. 4, pp. 755-760, 2013.

[97] B. Ricci, M. G. Scullica, F. Ricci, and A. Santo, "Iris vascular changes in newborns of diabetic mothers," Ophthalmologica, vol. 212, no. 3, pp. 175-177, 1998.

[98] A. Correa, S. M. Gilboa, L. M. Besser et al., "Diabetes mellitus and birth defects," American Journal of Obstetrics \& Gynecology, vol. 199, no. 3, pp. 237.e1-237.e9, 2008.

[99] U. J. Eriksson, J. Cederberg, and P. Wentzel, "Congenital malformations in offspring of diabetic mothers-animal and human studies," Reviews in Endocrine and Metabolic Disorders, vol. 4, no. 1, pp. 79-93, 2003.

[100] H. Reiher, K. Fuhrmann, K. P. Woltanski, E. Jutzi, H. Hahn von Dorsche, and H. J. Hahn, "Age-dependent insulin secretion of the endocrine pancreas in vitro from fetuses of diabetic and nondiabetic patients," Diabetes Care, vol. 6, no. 5, pp. 446-451, 1983.

[101] J. Jeon, M. Correa-Medina, C. Ricordi, H. Edlund, and J. A. Diez, "Endocrine cell clustering during human pancreas development," Journal of Histochemistry and Cytochemistry, vol. 57, no. 9, pp. 811-824, 2009.

[102] E. Taricco, T. Radaelli, G. Rossi et al., "Effects of gestational diabetes on fetal oxygen and glucose levels in vivo," BJOG, vol. 116, no. 13, pp. 1729-1735, 2009.

[103] J. Escobar, K. Teramo, V. Stefanovic et al., "Amniotic fluid oxidative and nitrosative stress biomarkers correlate with fetal chronic hypoxia in diabetic pregnancies," Neonatology, vol. 103, no. 3, pp. 193-198, 2013.

[104] T. K. Hytinantti, H. A. Koistinen, K. Teramo, S.-L. Karonen, V. A. Koivisto, and S. Andersson, "Increased fetal leptin in type I diabetes mellitus pregnancies complicated by chronic hypoxia," Diabetologia, vol. 43, no. 6, pp. 709-713, 2000.

[105] J. A. Widness, J. B. Susa, J. F. Garcia et al., "Increased erythropoiesis and elevated erythropoietin in infants born to diabetic 
mothers and in hyperinsulinemic rhesus fetuses," Journal of Clinical Investigation, vol. 67, no. 3, pp. 637-642, 1981.

[106] C. W. Pugh and P. J. Ratcliffe, "Regulation of angiogenesis by hypoxia: role of the HIF system," Nature Medicine, vol. 9, no. 6, pp. 677-684, 2003.

[107] P. Lassus, K. Teramo, I. Nupponen, H. Markkanen, K. Cederqvist, and S. Andersson, "Vascular endothelial growth factor and angiogenin levels during fetal development and in maternal diabetes," Biology of the Neonate, vol. 84, no. 4, pp. 287-292, 2003.

[108] R. Madazli, A. Tuten, Z. Calay, H. Uzun, S. Uludag, and V. Ocak, "The incidence of placental abnormalities, maternal and cord plasma malondialdehyde and vascular endothelial growth factor levels in women with gestational diabetes mellitus and nondiabetic controls," Gynecologic and Obstetric Investigation, vol. 65, no. 4, pp. 227-232, 2008.

[109] M. Loukovaara, P. Leinonen, K. Teramo, and S. Andersson, "Concentration of cord serum placenta growth factor in normal and diabetic pregnancies," BJOG, vol. 112, no. 1, pp. 75-79, 2005.

[110] M. Marini, D. Vichi, A. Toscano et al., "Effect of impaired glucose tolerance during pregnancy on the expression of VEGF receptors in human placenta," Reproduction, Fertility and Development, vol. 20, no. 7, pp. 789-801, 2008.

[111] A. M. Di Blasio, C. Carniti, P. Vigano, P. Florio, F. Petraglia, and M. Vignali, "Basic fibroblast growth factor messenger ribonucleic acid levels in human placentas from normal pathological pregnancies," Molecular Human Reproduction, vol. 3, no. 12, pp. 1119-1123, 1997.

[112] O. Grissa, A. Yessoufou, I. Mrisak et al., "Growth factor concentrations and their placental mRNA expression are modulated in gestational diabetes mellitus: possible interactions with macrosomia," BMC Pregnancy and Childbirth, vol. 10, article 7, 2010.

[113] T. Radaelli, A. Varastehpour, P. Catalano, and S. Hauguelde Mouzon, "Gestational diabetes induces placental genes for chronic stress and inflammatory pathways," Diabetes, vol. 52, no. 12, pp. 2951-2958, 2003.

[114] M. Nakano, K. Satoh, Y. Fukumoto et al., "Important role of erythropoietin receptor to promote VEGF expression and angiogenesis in peripheral ischemia in mice," Circulation Research, vol. 100, no. 5, pp. 662-669, 2007.

[115] L. Pietro, S. Daher, M. V. C. Rudge et al., "Vascular endothelial growth factor (VEGF) and VEGF-receptor expression in placenta of hyperglycemic pregnant women," Placenta, vol. 31, no. 9, pp. 770-780, 2010.

[116] T. M. Mayhew, D. S. Charnock-Jones, and P. Kaufmann, "Aspects of human fetoplacental vasculogenesis and angiogenesis. III. Changes in complicated pregnancies," Placenta, vol. 25, no. 2-3, pp. 127-139, 2004.

[117] M. Lappas, U. Hiden, G. Desoye, J. Froehlich, S. H.-D. Mouzon, and A. Jawerbaum, "The role of oxidative stress in the pathophysiology of gestational diabetes mellitus," Antioxidants and Redox Signaling, vol. 15, no. 12, pp. 3061-3100, 2011.

[118] S.-C. Chang and W.-C. V. Yang, "Hyperglycemia induces altered expressions of angiogenesis associated molecules in the trophoblast," Evidence-Based Complementary and Alternative Medicine, vol. 2013, Article ID 457971, 11 pages, 2013.

[119] P. Kleiblova, I. Dostalova, M. Bartlova et al., "Expression of adipokines and estrogen receptors in adipose tissue and placenta of patients with gestational diabetes mellitus," Molecular and Cellular Endocrinology, vol. 314, no. 1, pp. 150-156, 2010.
[120] J. B. Moreli, G. Morceli, A. K. C. De Luca et al., "Influence of maternal hyperglycemia on IL-10 and TNF- $\alpha$ production: the relationship with perinatal outcomes," Journal of Clinical Immunology, vol. 32, no. 3, pp. 604-610, 2012.

[121] J.-M. Atègbo, O. Grissa, A. Yessoufou et al., "Modulation of adipokines and cytokines in gestational diabetes and macrosomia," Journal of Clinical Endocrinology and Metabolism, vol. 91, no. 10, pp. 4137-4143, 2006.

[122] A. Lapolla, M. G. Dalfrà, M. Sanzari et al., "Lymphocyte subsets and cytokines in women with gestational diabetes mellitus and their newborn," Cytokine, vol. 31, no. 4, pp. 280-287, 2005.

[123] T. Hellwig-Bürgel, K. Rutkowski, E. Metzen, J. Fandrey, and W. Jelkmann, "Interleukin-1 $\beta$ and tumor necrosis factor- $\alpha$ stimulate DNA binding of hypoxia-inducible factor-1," Blood, vol. 94, no. 5, pp. 1561-1567, 1999.

[124] S. Jahan, C. M. Ahmed, R. Zinnat et al., "Influence of maternal diabetes on serum leptinemic and insulinemic status of the offspring: a case study of selected patients in a tertiary care hospital in Bangladesh," Diabetes and Metabolic Syndrome: Clinical Research and Reviews, vol. 5, no. 1, pp. 33-37, 2011.

[125] B. Persson, M. Westgren, G. Celsi, E. Nord, and E. Örtqvist, "Leptin concentrations in cord blood in normal newborn infants and offspring of diabetic mothers," Hormone and Metabolic Research, vol. 31, no. 8, pp. 467-471, 1999.

[126] K. Teramo, M. A. Kari, M. Eronen, H. Markkanen, and V. Hiilesmaa, "High amniotic fluid erythropoietin levels are associated with an increased frequency of fetal and neonatal morbidity in Type 1 diabetic pregnancies," Diabetologia, vol. 47, no. 10, pp. 1695-1703, 2004.

[127] M. M. Vela-Huerta, N. Amador-Licona, S. Anaya-Aguirre, J. M. Guizar-Mendoza, A. Velazquez-Bustamante, and B. MurilloOrtiz, "Insulin and leptin levels in appropriate-for-gestationalage infants of diabetic mother," Iranian Journal of Pediatrics, vol. 22, no. 4, pp. 475-480, 2012.

[128] M. Gauster, G. Desoye, M. Tötsch, and U. Hiden, "The placenta and gestational diabetes mellitus," Current Diabetes Reports, vol. 12, no. 1, pp. 16-23, 2012.

[129] L. Lassance, H. Miedl, M. Absenger et al., "Hyperinsulinemia stimulates angiogenesis of human fetoplacental endothelial cells: a possible role of insulin in placental hypervascularization in diabetes mellitus," The Journal of Clinical Endocrinology and Metabolism, vol. 98, no. 9, pp. E1438-E1447, 2013.

[130] U. Hiden, L. Lassance, N. Ghaffari Tabrizi et al., "Fetal insulin and IGF-II contribute to gestational diabetes mellitus (GDM)associated up-regulation of membrane-type matrix metalloproteinase 1 (MT1-MMP) in the human feto-placental endothelium," Journal of Clinical Endocrinology and Metabolism, vol. 97, no. 10, pp. 3613-3621, 2012.

[131] J. Lepercq, M. Cauzac, N. Lahlou et al., "Overexpression of placental leptin in diabetic pregnancy: a critical role for insulin," Diabetes, vol. 47, no. 5, pp. 847-850, 1998.

[132] P. S. Uzelac, X. Li, J. Lin et al., "Dysregulation of leptin and testosterone production and their receptor expression in the human placenta with gestational diabetes mellitus," Placenta, vol. 31, no. 7, pp. 581-588, 2010.

[133] H. J. Wolf, C.-F. Ebenbichler, O. Huter et al., "Fetal leptin and insulin levels only correlate in large-for-gestational age infants," European Journal of Endocrinology, vol. 142, no. 6, pp. 623-629, 2000.

[134] A. Perez-Perez, J. Maymó, Y. Gambino et al., "Insulin enhances leptin expression in human trophoblastic cells," Biology of Reproduction, vol. 89, no. 1, p. 20, 2013. 
[135] M. A. Nuamah, S. Yura, N. Sagawa et al., "Significant increase in maternal plasma leptin concentration in induced delivery: a possible contribution of pro-inflammatory cytokines to placental leptin secretion," Endocrine Journal, vol. 51, no. 2, pp. 177-187, 2004.

[136] A. Meisser, P. Cameo, D. Islami, A. Campana, and P. Bischof, "Effects of interleukin-6 (IL-6) on cytotrophoblastic cells," Molecular Human Reproduction, vol. 5, no. 11, pp. 1055-1058, 1999.

[137] M. Fasshauer, J. Klein, S. Neumann, M. Eszlinger, and R. Paschke, "Hormonal regulation of adiponectin gene expression in 3T3-L1 adipocytes," Biochemical and Biophysical Research Communications, vol. 290, no. 3, pp. 1084-1089, 2002.

[138] N. Hosogai, A. Fukuhara, K. Oshima et al., "Adipose tissue hypoxia in obesity and its impact on adipocytokine dysregulation," Diabetes, vol. 56, no. 4, pp. 901-911, 2007.

[139] M. Ballesteros, I. Simón, J. Vendrell et al., "Maternal and cord blood adiponectin multimeric forms in gestational diabetes mellitus: a prospective analysis," Diabetes Care, vol. 34, no. 11, pp. 2418-2423, 2011.

[140] D. Cortelazzi, S. Corbetta, S. Ronzoni et al., "Maternal and foetal resistin and adiponectin concentrations in normal and complicated pregnancies," Clinical Endocrinology, vol. 66, no. 3, pp. 447-453, 2007.

[141] M. H. Mohamed, G. I. Gad, H. Y. Ibrahim et al., "Cord blood resistin and adiponectin in term newborns of diabetic mothers," Archives of Medical Science, vol. 6, no. 4, pp. 558-566, 2010.

[142] D. J. Hill, G. J. M. Tevaarwerk, C. Caddell, E. Arany, D. Kilkenny, and M. Gregory, "Fibroblast growth factor 2 is elevated in term maternal and cord serum and amniotic fluid in pregnancies complicated by diabetes: relationship to fetal and placental size," Journal of Clinical Endocrinology and Metabolism, vol. 80, no. 9, pp. 2626-2632, 1995.

[143] J. A. Westgate, R. S. Lindsay, J. Beattie et al., "Hyperinsulinemia in cord blood in mothers with type 2 diabetes and gestational diabetes mellitus in New Zealand," Diabetes Care, vol. 29, no. 6, pp. 1345-1350, 2006.

[144] R. S. Lindsay, J. A. Westgate, J. Beattie et al., "Inverse changes in fetal insulin-like growth factor (IGF)-1 and IGF binding protein-1 in association with higher birth weight in maternal diabetes," Clinical Endocrinology, vol. 66, no. 3, pp. 322-328, 2007.

[145] Z.-C. Luo, A.-M. Nuyt, E. Delvin et al., "Maternal and fetal IGFI and IGF-II levels, fetal growth, and gestational diabetes," The Journal of Clinical Endocrinology \& Metabolism, vol. 97, no. 5, pp. 1720-1728, 2012.

[146] Y.-J. Liu, T. Tsushima, S. Minei et al., "Insulin-like growth factors (IGFs) and IGF-binding proteins (IGFBP-1, -2 and -3) in diabetic pregnancy: relationship to macrosomia," Endocrine Journal, vol. 43, no. 2, pp. 221-231, 1996.

[147] S. Roth, M. P. Abernathy, W.-H. Lee et al., "Insulin-like growth factors I and II peptide and messenger RNA levels in macrosomic infants of diabetic pregnancies," Journal of the Society for Gynecologic Investigation, vol. 3, no. 2, pp. 78-84, 1996.

[148] M. C. Gelato, C. Rutherford, G. San-Roman, S. Shmoys, and A. Monheit, "The serum insulin-like growth factor-II/mannose6-phosphate receptor in normal and diabetic pregnancy," Metabolism, vol. 42, no. 8, pp. 1031-1038, 1993. 

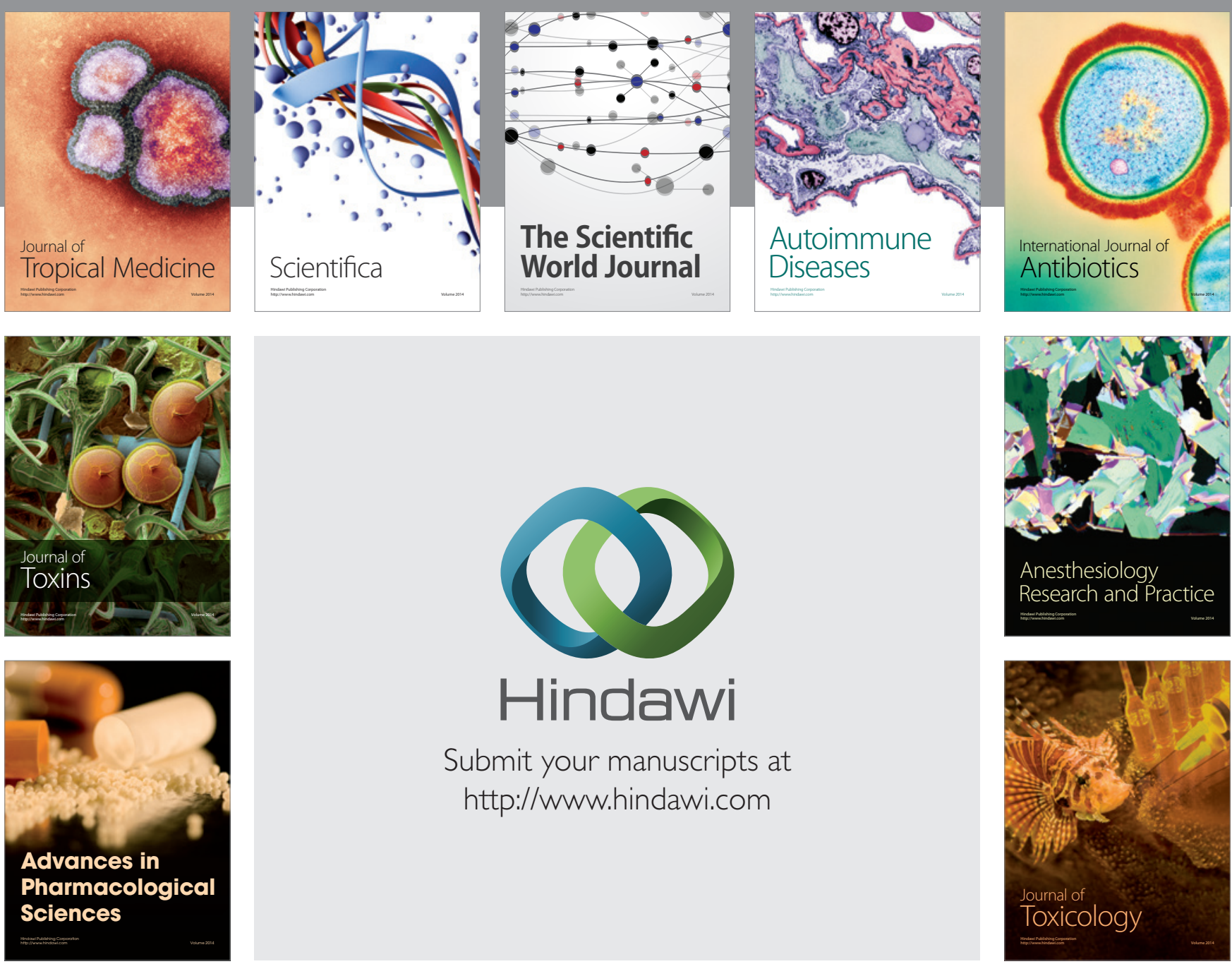

\section{Hindawi}

Submit your manuscripts at

http://www.hindawi.com
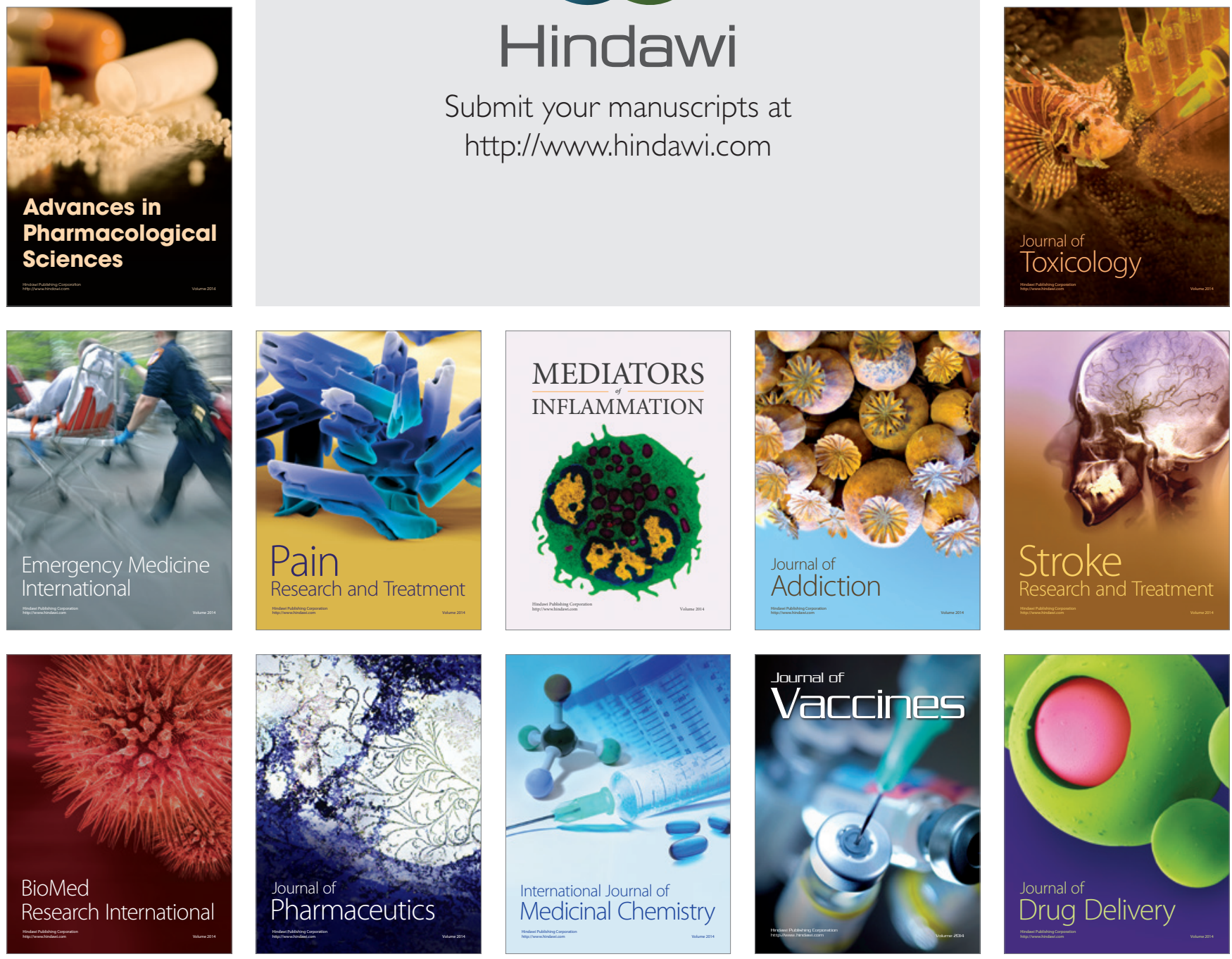